\title{
AS CONTRIBUIÇÓES DO AEE PARA O DESENVOLVIMENTO DAS CRIANÇAS COM DIFICULDADES DE APRENDIZAGEM
}

\author{
AEE'S CONTRIBUTIONS TO THE DEVELOPMENT OF CHILDREN WITH LEARNING \\ DIFFICULTIES
}

\section{Rafael Soares Silva}

Universidade Federal Rural do Rio de Janeiro, Rio de Janeiro, RJ, Brasil E-mail: doc.rafaelsoares@ gmail.com

\section{Izabel Rodrigues da Silva}

Centro Universitário UniFacid, Teresina, PI, Brasil. E-mail: izabel6418@gmail.com

\section{Jenerton Arlan Schütz}

Universidade Regional do Noroeste do Estado do Rio Grande do Sul, Ijuí, RS, Brasil. E-mail: jenerton. xitz@hotmail.com

Resumo: Este trabalho tem como proposta apresentar os resultados da pesquisa que tem como proposição compreender a contribuição do atendimento educacional especializado para desenvolvimento das crianças com dificuldades de aprendizagem no ensino fundamental. Os objetivos centram-se em entender a relaçấo da sala de $\mathrm{AEE}$ com a sala de aula regular; perceber a contribuição do atendimento educacional especializado para o desenvolvimento das crianças com NEE; identificar estratégias utilizadas no atendimento educacional especializado que contribuem para o desenvolvimento das crianças. Essa pesquisa é de natureza bibliográfica seguida de pesquisa de campo. Como instrumento na coleta de dados foi proposto um questionário com sete perguntas abertas, aplicado com dois professores e pedagogos. Tivemos como embasamento teórico autores como: FONSECA (2202), GIL (2008), GARCIA (2007), ROTTA (2006), LIBÂNEO (2006), dentre outros. Os resultados desses estudos nos permitiram entender que ainda falta muito para a inclusão realmente acontecer, mas que a escola se esforça na medida do possível para atender a todo tipo de necessidades, adquirindo recursos de acordo com a especificidade de cada um, para que possa ter um atendimento completo e suficiente para desenvolver suas habilidades. Mas ainda, observou-se a importante relação entre o professor da sala regular e o da sala do AEE, que planeje açóes pedagógicas voltadas para atingir objetivos que possam ajudar o aluno no âmbito educacional e social.

Palavras-chave: Atendimento Educacional especializado; AEE; Educação Especial.

Abstract: This work proposes to present the results of the research that aims to understand the contribution of specialized care for the development of children with learning difficulties in elementary school. The 
objectives are centered towards the ESA room with a regular classroom; verified the contribution of specialized educational assistance to the development of children with SEN; identify standardized, specialized educational services that contribute to the development of children. This research is of a bibliographic nature followed by field research. As a tool in data collection, a questionnaire with seven open questions was proposed, applied with two teachers and pedagogues. We had as theoretical basis authors such as: FONSECA (2202), GIL (2008), GARCIA (2007), ROTTA (2006), LIBÂNEO (2006), among others. The results of these studies allow us to understand that there is still much to be done for inclusion to actually happen, but that the school strives as far as possible to meet all types of needs, acquiring resources according to the specificity of each one, so that it can have a complete and sufficient service to develop your skills. But still, there was an important relationship between the teacher of the regular room and the AEE room, who plans pedagogical actions aimed at achieving the goals that can help the student in the educational and social sphere.

Keywords: Specialized Educational Service; ESA; Special education.

\section{Introduçáo}

$\Lambda$ educação inclusiva é um princípio que tem se destacado, ganhando assim espaço

Ae investimentos por parte das políticas públicas. Esse investimento é um passo importante para garantir que os alunos com deficiência tenham a atenção que precisam e também aprendam de forma afetiva, assim como os demais, pois é fato que um professor da educaçáo básica, que tem uma turma com muitos alunos, não consegue se dedicar integralmente a turma e ainda tratar de forma atenciosa o aluno com deficiência, trabalhando assim suas particularidades e melhorando o seu desenvolvimento.

Esse trabalho tem como tema "A contribuição do atendimento educacional especializado para o desenvolvimento das crianças com dificuldades de aprendizagem no ensino fundamental".

Como objetivo geral tem-se o seguinte: analisar a contribuição do atendimento educacional especializado para o desenvolvimento das crianças com dificuldades de aprendizagem no ensino fundamental. E como objetivos específicos destacamos: entender a relação da sala de AEE com a sala de aula normal; perceber a contribuição do atendimento educacional especializado para o desenvolvimento das crianças com NEE; identificar estratégias utilizadas no atendimento educacional especializado que contribuem para o desenvolvimento das crianças.

O presente trabalho tem como perguntas norteadoras: Qual a contribuição do atendimento educacional para desenvolvimento das crianças? Como é realizado o atendimento educacional especializado? As professoras são e/ou estão preparadas para trabalhar com AEE?

A escolha desse tema surgiu a partir do estágio obrigatório no ensino fundamental ao qual tivemos a oportunidade de visitar a sala do AEE. Esta por sua vez, se encontrava equipada com recursos diversos, e em conversa com a professora, pudemos notar a sua satisfação e alegria em estar com as crianças, ajudando os alunos a desenvolverem habilidades, que por muitas vezes são excluídas por suas limitaçôes. No $\mathrm{AEE}$, os professores desenvolvem atividades e auxiliam também na socialização com outras crianças que possuem deficiência. Com isso, percebe-se que há assim diversidades entre as pessoas e que cada uma tem sua especificidade, podendo participar de brincadeiras, atividades coletivas e gastar energia, o que auxilia no processo ensino- 
aprendizagem desses alunos que requer desse professor uma atenção a mais na hora de aprender.

Esse trabalho é de grande relevância para futuros professores no que tange a contribuição do AEE para o desenvolvimento das crianças com dificuldades de aprendizagem, mostrar os avanços na aprendizagem do aluno com NEE na sala de ensino regular e para informar pais de alunos que precisam desse atendimento educacional.

A referente pesquisa é qualitativa, uma vez que a mesma visa compreender a natureza de um fenômeno social, também é de cunha bibliográfico que se caracteriza por colocar o pesquisador em contato direto com tudo o que foi escrito ou dito. Após a análise bibliográfica partimos para o trabalho de campo, que é caracterizada pela aplicaçáo de um questionário, a três professores e composta por sete questóes abertas relacionadas a aprendizagem e ao conhecimento, isto é, com o intuito de obter informaçóes sobre a contribuição da sala de AEE para o desenvolvimento dos alunos com necessidades especiais. Os autores FONSECA (2002), GIL (2008), GARCIA (2007), ROTTA (2006), LIBÂNEO (2006), fundamentaram essa pesquisa.

\section{Atendimento Educacional Especializado}

O AEE é o atendimento educacional especializado veio para auxiliar na educação de crianças especiais, contribuindo para o desenvolvimento dentro e fora da escola, onde o mesmo é realizado dentro do próprio espaço físico da escola. No entanto, esse atendimento também pode ser disponibilizado em centros especializados, no caso de a escola não possuir a sala de AEE é ofertado obrigatoriamente pelos sistemas de ensino.

O Atendimento Educacional especializado- AEE, é um serviço da educação especial que "[...] identifica, elabora e organiza recursos pedagógicos e de acessibilidade, que eliminem as cadeiras para a plena participação dos alunos considerando suas necessidades especificas (SEESP/MEC, 2008).

Nota-se que o AEE faz parte da política Nacional da Educação Especial na perspectiva da Educação Inclusiva e os alunos são atendidos em uma sala chamada de sala de recursos multifuncionais e faz parte do projeto político pedagógico da escola. Os alunos encaminhados para a sala de AEE, são aqueles que apresentam alguma deficiência seja ela física, mental, intelectual ou sensorial, assim também como os alunos que possuem transtornos globais do desenvolvimento, ou seja, alunos com síndrome do espectro autista, psicose infantil e alunos com superdotação/ altas habilidades.

Para além disso, é importante tomar nota de que ao serem encaminhadas para o AEE, as matriculas desses alunos, está condicionada a matricula do ensino regular dos mesmos. O AEE pode funcionar também em centros de atendimentos público ou privado devendo seguir as orientaçôes da política Nacional de Educação Especial na perspectiva da Educação Inclusiva, e está de acordo também com diretrizes operacionais de Educação especial para o AEE na Educação básica. (MEC/SEFSP, 2009).

\section{Articulaçáo entre Escola Comum e Educaçáo Especial: açóes e responsabilidades compartilhadas}

A educação especial deve refazer caminhos para se articular com a escola comum, quebrando tabus de que a escola comum é somente para alunos ditos "normas" deixando de 
lado os alunos com necessidades especiais. É necessário que haja mudanças para que não exista escolas divididas e que esses alunos não fiquem isolado, excluídos em ambientes educacionais. É importante que os alunos especiais se sintam seguros e inclusos dentro escola, participando de atividades e convivendo com os alunos "normas" e isso deve ocorrer em todos os níveis e etapas da escolarização dos alunos especiais. O convívio com outras crianças auxilia no desempenho e no desenvolvimento do aluno especial, fazendo com que estes não se sintam excluídos, gerando assim um emaranhado de experiências e ajuda mútua, enxergando e aceitando o outro com suas diferenças e limitaçôes.

Os professores devem trabalhar em parceria para que os objetivos traçados pela equipe sejam alcançados, sempre visando o desenvolvimento pleno do aluno. $O$ professor da sala comum ensina as áreas e competências do conhecimento e o professor de AEE atua na complementação dessa formação, utilizando os recursos específicos que favorecem na sua autonomia e independência desse aluno. A coordenação pedagógica pode articular atividades para o professor do AEE, visando sempre à melhoria do ensino e ao benefício da criança.

Diante disso, os profissionais deverão estabelecer uma articulação com os professores da classe regular no que diz respeito à disponibilização de recursos pedagógicos, serviços e estratégias que promovam a participação dos alunos nas atividades escolares. Em se tratando do atendimento a crianças com necessidades educacionais especiais e da importância da aprendizagem para o desenvolvimento das mesmas, faz-se necessário, uma prática docente, que demonstre a importância da educação da criança com deficiência, junto as demais crianças, destacando a relevância da ação educativa e interação social para o seu desenvolvimento (VYGOTSKY, 1989).

Assim as ações compartilhadas vão desde o estudo e a identificação do problema pelo qual um aluno é encaminhado à educação especial, compartilhamento das estratégias a seres desenvolvidas no AEE com todos os membros da equipe escolar, o desenvolvimento de recursos e materiais didáticos para o atendimento do aluno em sala de aula e o acompanhamento conjunto da utilização dos recursos e do progresso do aluno no processo de aprendizagem, dentre outros. Assim, no contexto intraescolar, os professores podem perceber o que está funcionando ou o que pode ser melhorado através da parceria entre os professores da sala comum e da sala de AEE. Já no contexto extraescolar, essas articulaçôes ajudam as famílias e os demais profissionais que participam desse processo. Logo, as articulaçóes só podem ser efetivadas se o AEE estiver dentro do projeto político pedagógico, para que os demais eixos dessas articulaçóes entre ambas as partes sejam contemplados, e com isso ter uma educação inclusiva de fato.

Logo, a educação inclusiva precisa de reforma educativa, nos métodos e práticas de ensino, para além da acessibilidade, promover as habilidades desse alunado e garantir a sua permanência, bem como a igualdade entre os alunos, no sentido de respeito à heterogeneidade, desenvolvendo um resultado significativo na vida escolar de todos estes, mas preocupando-se principalmente com os sujeitos que se encontram a margem da exclusão e, para isso a qualificação docente é um ponto fundamental para a efetivação da política de inclusão, sendo que esta possui papel ativo e intervenção direta junto aos alunos com NEE e necessita, portanto, de formaçáo adequada para atender de forma significativa promovendo o desenvolvimento e a inclusão desses sujeitos (RODRIGUES, 2008). 


\section{O Projeto Político Pedagógico e o AEE}

Os obstáculos que impedem uma inclusão com qualidade e igualdade vão desde a estabilidade de práticas tradicionais e similitude de ensino até carências de recursos humanos, cursos de capacitação e de acessibilidade. Além disso, verificamos um novo problema emergente advindos com a inclusão que é a grande lotação das turmas de inclusão e a decorrente falta de escolas para atender toda a demanda de estudantes, visto que vem tendo um grande aumento com o passar do tempo.

Nessa perspectiva, vislumbramos a construção de um Projeto Político Pedagógico Escolar participativo que eleve a qualidade de atendimento dos Alunos com Necessidades Educacionais Especiais (ANEEs) e contemple planos de açóes inclusivos, destacando possíveis intervenções e adequaçôes organizativas, metodológicas e programáticas para melhor atender essa clientela, isto é, o projeto político pedagógico é o instrumento por excelência para melhor desenvolver o plano de trabalho eleito e definido por um coletivo escolar. Ele reflete a singularidade do grupo que o edificou, suas escolhas e especificidades (SILVA, 2014).

Diante das reais necessidades de construir um PPP que contemple às necessidades dos ANEEs, bem como a valorização das diferenças e a igualdade de oportunidades de aprender e interagir com seus pares é que este estudo foi constituído, com o objetivo geral de contribuir com gestores e professores com possíveis reflexôes e propostas de ação para educação Inclusiva frente à construção do Projeto Político Pedagógico. Para tanto é necessário que se fortaleçam e se estreitem as relaçôes entre escola e sistema de ensino, pois quando construirmos os projetos de nossas escolas planejamos o que temos intenção de fazer e de realizar, projetamos para adiante com base no que temos e buscando o possível. É um plano de transformação da realidade da escola (VEIGA, 2005).

Contudo, o AEE deve está incluso no PPP da escola e toda a equipe escolar precisa se organizar, planejar e traçar metas e propostas conjuntas para melhorar a escola comum. Sobre isso, temos que o projeto representa a oportunidade de a direção, a coordenação pedagógica, os professores e toda a comunidade escolar, definir seu papel estratégico na educação das crianças e jovens, organizar suas açóes, visando a atingir os objetivos que se propóem. O PPP é o norteador da vida escolar (LIBÂNEO, 2003).

O PPP acompanha a articulação do professor da sala do AEE e os professores das salas comuns, ele monitora a produçáo dos materiais didáticos e os recursos que precisam para fazer. Ele também inclui outros tipos de recursos, equipamentos e suportes que o professor do AEE indique o que necessita e dá condiçóes para manter, melhorar e/ou ampliar os espaços das salas de recursos multifuncionais. O PPP no caso do AEE, organiza horários, faz levantamentos de material didático, orienta as famílias e os professores que estão envolvidos com o AEE e os da sala comum (SILVA, 2014).

O que se espera com a construção do Projeto Político Pedagógico é que a escola possibilite em sua prática pedagógica, a formação de cidadãos capazes de compreender a sociedade a qual estão inseridos, considerar seus aspectos contraditórios e atuar nela de forma consciente, lutando para superar as relaçóes atuais e, ao mesmo tempo, construir modos de vida mais igualitários, mais dignos e menos individualizados. 


\section{A Organizaçáo e a oferta do AEE}

De acordo com o decreto $n^{\circ}$ 6.517, de 17 de setembro de 2008, que discorre sobre o AEE, e destina recursos do Fundo Nacional de Desenvolvimento da Educação Básica - FUNDEB, permite a dupla matricula desses alunos em sala de aula comum e no AEE, de acordo com o registro no Censo Escolar. Com esse decreto é possível investir na formação continuada dos professores, no espaço físico e em móveis, na compra de novos recursos de tecnologia assistia e para a manutenção e organização que precisar na sala de recursos multifuncionais (BRASIL, 2007).

Quando o AEE acontece de forma extraescolar, no caso dos centros de atendimento educacional especializado público ou privado sem fins lucrativos, ele deve seguir as Diretrizes Operacionais para o Atendimento Educacional Especializado (2009) e também as normativas estabelecidas pelo Conselho de Educação do respectivo sistema de ensino para a autorização e funcionamento do AEE. De acordo com as Diretrizes, para o financiamento do AEE, são exigidas as seguintes condiçôes: matricula na classe comum e na sala de recursos multifuncional da mesma escola pública, matrícula na classe comum e na sala de recursos multifuncional de outra escola pública, matricula na classe comum e em centro de atendimento educacional especializado e matricula na classe comum e no centro de atendimento educacional especializado privado sem fins lucrativos (BRASIL, 2008).

Porquanto, o AEE se organiza de acordo com a especificidade de cada aluno, levando em consideração a vida deste e depois a deficiência, saber as causas, fazer um diagnóstico, para depois desenvolver as estratégias para a respectiva criança. Cada aluno tem seu horário especifico de acordo com sua deficiência, para melhor utilizar os recursos e também para a professora executar seu plano de aula de acordo com a criança. Mas é possível atender grupos de alunos, se esses compartilharem das mesmas necessidades, proporcionando-se com isso a socialização entre eles.

Náo podemos comparar o AEE com sala de reforço, ele tem atendimento e funçôes específicas do próprio ensino especial e os planos do professor são voltados para a escolha de recursos e equipamentos específicos de acordo com a deficiência e necessidade de cada aluno. O professor do AEE deve estar sempre conectado, mantendo a parceria e o diálogo com o professor da sala regular, para juntos avaliarem e ajudarem na superação dos obstáculos, ou seja, as atividades desenvolvidas no AEE diferenciam-se daquelas realizadas em sala regular. Esse atendimento exerce papel complementar e/ou suplementar na formação dos alunos, tendo como meta a autonomia e independência do mesmo dentro e fora da escola (BRASIL, 2008).

O professor da Educação Especial deve estar ciente que ele é importante para esse processo e que suas atividades promovam crescimento e ajudem no processo ensino-aprendizagem desses sujeitos. Mas também, o professor da sala regular juntamente com o professor do AEE avalia se os recursos e se os atendimentos estáo garantindo o avanço do aluno nas atividades escolares, se não, serão planejadas outras açôes e novas estratégias e aplicação de novos recursos.

Nessa perspectiva, são recursos do AEE: materiais didáticos e pedagógicos acessíveis (livros, desenhos, mapas, gráficos e jogos táteis, em libras, em Braile, em caráter ampliado, com contraste visual, imagéticos, digitais, entre outros), tecnologias de informação e de comunicação (TICS) acessíveis (mouses e acionadores, teclados com colmeias, sintetizadores de voz, linha 
Braile, entre outros) recursos ópticos; pranchas de CAA, engrossadores de lápis, ponteira de cabeça, piano inclinado, tesouras acessíveis, quadro magnético com letras imantadas, entre outros (BRASIL, 2008).

Em suma, para que o processo de desenvolvimento tenha sucesso, é preciso que a família, a escola e a sociedade se unam e firmam o compromisso de ajudar nesse processo. Para tanto, é necessária uma nova estrutura organizacional, com currículos flexíveis, estratégias teóricas e metodológicas eficientes, recursos e parcerias com a comunidade que sejam de fato concernentes com a realidade existente e os princípios de uma educação para todos.

\section{A formaçáo de Professores para o AEE}

Para atuar no AEE os professores devem ter formação específica e precisam atender aos objetivos da educação especial. Quando os professores buscam por uma formação continuada, eles se atualizam e ampliam seus conhecimentos com conteúdo próprio para o atendimento especializado. Um dos objetivos que consiste no PPP é a formação de professores, tanto da sala do AEE, quanto o da sala regular.

Logo, para atuar na educação especial, o professor deve ter como base formação, inicial e continuada, conhecimentos gerais para o exercício da docência e conhecimentos específicos da área. Essa formação possibilita a atuação no atendimento educacional especializado e deve aprofundar o caráter interativo e interdisciplinar da atuação nas salas comuns do ensino regular, nas salas de recursos, nos centros de atendimento educacional especializado, nos núcleos de acessibilidade das instituiçóes de educação superior, nas classes hospitalares e nos ambientes domiciliares, para a oferta dos serviços e recursos da educação especial (BRASIL, 2008).

A proposta em relação à formação em nível de aperfeiçoamento e especialização é que sejam em ações de formação fundamentadas em metodologias ativas de aprendizagem, tais como estudos de caso, Aprendizagem Baseada em Problemas (ABP) ou Problem Based Learning (PBL), Aprendizagem Baseada em Casos (ABC), Trabalhos com Projetos, Aprendizagem Colaborativa em Rede (ACR), entre outras.

Nesse contexto, a formação pode estimular o desenvolvimento profissional dos professores, no quadro de uma autonomia contextualizada da profissão docente. Importa valorizar paradigmas de formação que promovam a preparação de professores reflexivos, que assumam a responsabilidade do seu próprio desenvolvimento profissional e que participem como protagonistas na implementação das políticas educativas (NÓVOA, 1995).

Mais ainda, segundo as Diretrizes Nacionais de Educação Especial para a Educação Básica e a Política Nacional de Educação Especial na Perspectiva da Educação Inclusiva, o Atendimento Educacional Especializado, realizado em Sala de Recurso Multifuncional, é um serviço que deverá ser realizado por um professor Graduado em Curso de Licenciatura em Educação Especial ou em uma de suas áreas, preferencialmente de modo concomitante e associado à licenciatura para Educação Infantil ou para os anos iniciais do Ensino Fundamental, com complementação de estudos ou pós-graduação em áreas específicas da Educação Especial (BRASIL, 2001; 2008). 


\section{Metodologia}

Esse trabalho se iniciou a partir do estágio obrigatório em educação especial, qual conhecemos a sala de recursos multifuncionais do AEE, e despertou-nos a curiosidade de saber como aconteciam os atendimentos, quem poderia ser atendido e o que significa essa sala para os alunos e professores.

Para a realização dessa pesquisa foi utilizada a abordagem metodológica qualitativa, (GASKELL E GEORGE, 2003) que envolve a obtenção de dados descritivos em contato direto com o problema estudado e por meio de um questionário direcionados aos professores da escola.

A presente pesquisa é de cunho bibliográfico, pois se utiliza de recursos bibliográficos, baseada em referências teórica como livros, artigos acadêmicos e internet, os quais possibilitaram um suporte para a construção do mesmo. Segundo Fonseca (2002):

A pesquisa bibliográfica é feita, a partir do levantamento de referências teóricas já analisadas, e publicadas por meios escritos e eletrônicos, como livros, artigos científicos, páginas de web sites. Qualquer trabalho científico inicia-se com uma pesquisa bibliográfica, que permite ao pesquisador conhecer o que já se estudou sobre o assunto. Existem, porém pesquisas científicas que se baseiam unicamente na pesquisa bibliográfica, procurando referências teóricas publicadas com o objetivo de recolher informaçóes ou conhecimentos prévios sobre o problema a respeito do qual se procura a resposta (FONSECA, 2002, p. 32).

Certamente, é também um estudo de campo, pois buscamos dados juntos à realidade específica do problema para podermos ter uma dimensão desses atendimentos, fazendo estudo, entrevistas para colher informaçóes verídicas sobre nossa pesquisa.com efeito, para Fonseca (2002):

A pesquisa de campo caracteriza-se pelas investigaçóes em que, além da pesquisa bibliográfica e/ou documental, se realiza coleta de dados junto a pessoas, com o recurso de diferentes tipos de pesquisa - pesquisa ex-post-facto, pesquisa-açáo, pesquisa participante, etc.) (FONSECA, 2002).

De certo, para esse trabalho utilizamos apenas o questionário como instrumento de pesquisa. Destarte, questionário é um instrumento de coleta de informação, utilizado numa sondagem ou inquérito.

De acordo com Gil (2008):

Questionário pode ser definido como uma técnica de investigação social composta por um conjunto de questóes que são submetidas às pessoas com o propósito de obter informaçôes sobre conhecimentos, crenças, sentimentos, valores, interesses, expectativas, aspirações, temores, comportamento presente e passado (GIL, 2008, p. 121).

Nesse caso, foi aplicado um questionário com sete perguntas abertas. Os sujeitos da pesquisa foram três pessoas: a pedagoga da escola, a professora da sala de recursos multifuncionais do AEE e uma professora da sala regular da $1^{\text {a }}$ série do fundamental, ao qual possui três crianças especiais que frequentam esta escola. O lócus foi a Escola Municipal Lunalva Costa - uma instituição pública mantida pela Prefeitura Municipal de Teresina, através da Secretaria Municipal de Educação e Cultura - SEMEC. Se encontra localizada no Bairro Dirceu II na zona Sudeste da capital. A escola atende 744 crianças do ensino fundamental do $1^{\circ}$ ao $9^{\circ}$, na faixa etária de 06 a 14 anos, nos turnos manhã e tarde, sendo seu horário de funcionamento das $07 \mathrm{~h}$ 
às $11 \mathrm{~h} 20 \mathrm{~min}$ e das $13 \mathrm{~h} 00 \mathrm{minas}$ às $17 \mathrm{~h} 20 \mathrm{~min}$.

Sua estrutura física composta por 30 salas, sendo 12 salas de aula do $1^{\circ}$ ao $9^{\circ}$ ano, sendo duas uma sala o projeto mais educação, 17 salas restantes abrigam uma biblioteca com um vasto acervo de livros, sala de vídeo, sala de computação, banheiros masculinos e femininos todos adaptados para deficientes, secretaria, sala dos professores, diretoria, coordenaçáo pedagógica, uma ampla cantina e dois almoxarifados, a escola também possui um pátio coberto logo na entrada com uma área livre, também consta em suas instalaçôes uma quadra de esportes e um mini parquinho no fundo da escola. A escola conta atualmente com 54 funcionários, incluindo professores efetivos, estagiários, uma pedagoga, uma diretora e seu vice, e os funcionários de serviços gerais.

$\mathrm{Na}$ escola também funciona o projeto segundo tempo e o AEE que é um apoio psicopedagógico prestado as crianças especiais durante o contra turno das aulas. Durante quatro horas semanais ou duas vezes por semana, dependendo da necessidade do aluno e da disponibilidade do responsável pela criança, existe entre os profissionais da escola a consciência da necessidade de se prestar serviços de qualidade a comunidade, sendo em sua maioria pessoas de baixa renda. Os pais ou responsáveis em grande parte veem a escola como um local onde os seus filhos podem ser cuidados e educados, a maioria deles em tempo integral. As reuniôes e os encontros com os pais ocorrem quando os pais ou educadores precisam discutir assuntos específicos com os responsáveis.

\section{Análise e discussáo de dados}

Essa etapa do estudo apresenta a análise das questôes e respostas que foram analisadas durante a pesquisa na escola. Para que se obtivesse uma análise comparativa entre a realidade vivenciada e o processo de inclusáo de crianças com necessidades especiais no ensino regular, foram levadas em consideração as observaçôes feitas e que buscaram descrever e investigar o ambiente de aprendizagem e os procedimentos utilizados, verificando se a inclusão em sala de aula acontece de fato. E, de acordo com os objetivos estabelecidos anteriormente e conforme os dados obtidos durante o trabalho de pesquisa, a análise foi concomitante à coleta de dados, emergindo assim sete categorias de análise. A seguir serão relatados os dados dos questionários e respectivamente a categorização dos dados dos mesmos.

Para preservar a identidade dos profissionais envolvidos na pesquisa, utilizamos as siglas PE (Pedagogo) PAEE (Professor do AEE) PSR (Professor da Sala Regular) para nomear os sujeitos.

Quando perguntado o que é necessário para a criança ser encaminhada para o atendimento educacional especializado, obteve-se como resposta

PE - No ato da matrícula, pergunta-se ao pai ou responsável se a criança ou adolescente tem algum problema de saúde ou dificuldade de aprendizagem. Em caso afirmativo, pede-se o laudo médico. No diagnóstico em sala de aula, o (a) docente, mediante suspeita, encaminha à coordenação que, por sua vez, encaminha à docente do AEE para realização de teste diagnóstico a fim de se tomar as medidas necessárias para se assegurar os direitos dos mesmos.

PAEE - Quando se percebe que a criança tem alguma deficiência, encaminha para a sala de AEE para se realizar um diagnóstico, e se confirmado, ela é inserida, dependendo do grau de 
deficiência da mesma. Em sala de aula se o professor (a) observa o aluno, e se detectado alguma dificuldade na aprendizagem nós a encaminhamos.

Pode-se observar nas respostas colhidas que todas mencionam que é preciso um diagnóstico para que a criança seja encaminhada e atendida pela a sala de AEE - PSR.

De acordo com Garcia (2007, p. 181):

Vale sempre enfatizar que a inclusão de indivíduos com necessidades educacionais especiais na rede regular de ensino não consiste apenas na sua permanência junto aos demais alunos, nem na negação dos serviços especializados àqueles que deles necessitem Ao contrário implica em uma reorganização do sistema educacional o que acarreta a revisão de antiga concepção e paradigmas educacionais, na busca de se possibilitar o desenvolvimento cognitivo, cultural e social desses alunos, respeitando suas diferenças e atendo às suas necessidades (GARCIA, 2007, p. $181)$.

Dizemos entáo, que os professores devem estar preparados e atentos para detectar algumas dificuldades e criar condiçóes para que esse aluno venha se sentir acolhido, propor atividades diferentes que ajude em seu desenvolvimento e realizar momentos para os discentes de salas regulas e salas de AEE discutirem atividades e meios para uma melhor chance de desenvolvimento de suas habilidades sociais.

Em seguida foi questionado a faixa etária das crianças do atendimento educacional especializado. Obtivemos as seguintes respostas:

PE - Não. Tem que ser aluno da rede municipal de ensino e ter o perfil para o atendimento. Independentemente de ser aluno da escola — núcleo (AEE).

PAEE - Náo. Desde que seja aluno da rede pública de ensino e que frequente a escola regularmente.

PSR - Não. Qualquer idade, depende mais de qual a deficiência o aluno é acometido.

Pode-se notar que ambas as três respostas foram negativa em relação ao limite de idade para frequentar a sala de AEE, basta estar matriculado e frequentar regularmente a escola.

Sobre isso esclarece Rotta (2006, p. 19):

Muitas vezes a criança em idade escolar é discriminada e até emocionalmente agredida, pois não está apresentando o desempenho escolar esperado; no entanto, o responsável por tal situação pode estar no ambiente que a rodeia. As dificuldades socioeconômicas e afetivo-culturais podem interferir no ato de aprender, independentemente da vontade da criança. A equipe multidisciplinar e interdisciplinar só tem sucesso quando age de forma integrada com a família e com a escola. Dessa integração resulta um melhor entendimento da situação e um maior aproveitamento, pela criança, das terapias).

Quanto mais cedo a descoberta da deficiência melhor para criança, para o seu desenvolvimento e assim o avanço no ensino-aprendizagem, dependendo da deficiência e seu desenvolvimento, menos tempo irá passar na sala de AEE, mas tem algumas deficiências que alunos deverão sempre continuar sendo assistidos pelo AEE. Portanto é fundamental que a família compreenda a eficácia de inserir o aluno na sala de AEE o mais cedo possível.

Quando indagados se o tempo em que a criança permanece no atendimento educacional especializado é suficiente, os professores responderam que:

PE- $\mathrm{O}$ atendimento é realizado em 4 horas semanais, que podem ser divididas em dois 
atendimentos com duas horas de duração fica a critério da professora em parceria com os pais ou responsável. Nem sempre, porque depende do perfil do aluno.

PAEE - São 4 horas semanais. Que pode ser dividida em 2 vezes por semana de acordo com a disponibilidade dos pais e da rotina da criança. Não, porque depende da deficiência da criança.

PSR - Não temos essa resposta, sempre vai existir uma insuficiência para o aluno especial hem alguma coisa $\mathrm{O}$ tempo certo é esse, de quatro horas semanais, distribuindo de acordo com a disponibilidade de ambas.

De acordo com as respostas dadas pelas professoras é possível entender que o atendimento de quatro em quatro horas semanais não é suficiente, pois depende também da deficiência do aluno e sua realidade de vida, dependendo também da melhor forma de se organizar do professor.

O tempo de aprendizagem exige que se considerem as diferentes ritmas e experiências, carecendo de diferentes oportunidades, para a devida mediação entre o que o aluno consegue realizar sozinho e aquilo que exige a mediaçáo pedagógica. Relacionados aos diferentes tempos, há que se forjar os adequados espaços, com os imprescindíveis recursos. (SAVIANI, 2003, p. 6).

Percebemos segundo Saviani, esse tempo de aprendizagem dependerá da experiência que o aluno já traz consigo e da forma como ele vive, para a professora exige um conhecimento mais aprofundado deste aluno para que prepare a melhor metodologia e como usar o espaço.

No que diz respeito aos recursos utilizados no atendimento educacional especializado, se são suficientes ou não, obtivemos:

PE - Não. Porque são inúmeras as deficiências e que geram demandas bem específicas nos ambientes escolares. Mesmo aqueles que possuem as salas de recursos tipo I e tipo II não são capazes de atender com eficácia a toda a demanda existente. As escolas se adequam na medida do possível, a demanda real.

PAEE - Sim. Quando necessitamos de um material, confeccionamos ou compramos. O MEC nos supre com uma imensa variedade do que pedimos e dependendo das necessidades aqui estabelecidas.

PSR - Não. A própria professora confecciona o próprio material e a escola ajuda de acordo com a deficiência de cada aluno. Mas a sala é bem estruturada faltando apenas a máquina Braille.

Pode se observar nas respostas que para PE se refere que a sala de recursos é insuficiente para atender a todos os alunos; para a PAEE ela diz que o MEC repassar o que é necessário e ela confecciona o que falta para ajudar no desenvolvimento da criança. Já para PSR a própria professora faz, mas diz que a sala é bem estruturada.

Existem várias formas com as quais os alunos na sala de recursos poderão ser avaliados, através de desenhos, pinturas, modelagem, maquetes, usar jogos educativos para expressar o nível do seu conhecimento em determinada tarefa. (ESAP, 2012).

Segundo Esap, o professor não precisa se prender somente à materiais caros ou objetos, e sim, que poderá trazer um grande conhecimento para esse aluno através dos meios mais simples e criativos. Por outro lado, esclarece Mazzotta (1993, p. 19) quando diz que "as instituiçôes escolares devem contar com os meios adequados para atendê-los, ainda que isto implique a 
provisão de recursos que usualmente não fazem parte de sua organização".

Sendo assim, em situaçóes especiais ou não usualmente disponíveis no sistema educacional, no que diz respeito às situaçóes de aprendizagem, esses alunos requerem auxílios e serviços especiais para que sua educação se desenvolva de forma produtiva.

Ao se questionar como acontece a relação entre o professor do atendimento educacional especializado e o professor da sala regular, pudemos obter:

PE - O planejamento é realizado conforme resultado do diagnóstico individual, baseado no potencial que o aluno apresenta para tentar desenvolvê-lo A professora conversa com os professores titulares das turmas de origem dos educandos atendidos para verificar se os objetivos propostos foram alcançados. Realiza visitas nessas salas de aula para observar e orientar os docentes.

PAEE - É bom, a professora da sala regular ajuda, informando os avanços e as dificuldades dos alunos, para que a mesma procure focar em atividades voltadas para desenvolver as habilidades dos alunos - PAEE.

PSR - É boa. Sempre há um diálogo sobre o desenvolvimento das crianças.

Dito isto, podemos observar que para a PE a relação é importante haver planejamento com todos os envolvidos com a criança especial e para PAEE sempre uma ajuda à outra com trocas de informaçôes sobre aluno. Já para PSR o diálogo sempre é importante para desenvolvimento da mesma. Considerando o exposto observamos segundo Libâneo (2006), que com a orientação da coordenação pedagógica e havendo um clima de elaboração, pode se chegar à prática dos professores ao observarem as aulas uns dos outros e fazerem uma reflexão conjunta para que se ajudem reciprocamente.

Sendo assim:

Cabe ao professor do AEE a partir de observação criteriosas, ajustar suas intervençôes pedagógicas ao processo de aprendizagem dos diferentes alunos, de modo que lhes possibilite um ganho significativo do ponto de vista educacional, afetivo e sócio cultural (PRADO \& FREIRE, 2001, p. 5).

Com isso, é importante que haja um planejamento conjunto com os professores do AEE e o professor da sala regular para traçar metas e alcançar os objetivos para que o aluno consiga desenvolver suas habilidades e possa ser inserido no ambiente acolhedor e pensar no seu futuro.

Outro aspecto importante diz respeito ao atendimento educacional especializado, se o mesmo tem realmente contribuído com a aprendizagem das crianças. Nessa direção, identificamos nas falas analisadas:

PE - Nem sempre, dependendo do grau de comprometimento da criança ou do adolescente. Às vezes contribui no sentido da socialização e adaptação. Serve também para ensinar os ditos "normais" a conviver com as diferenças.

PAEE - Espero que sim, embora essa não seja o nosso único objetivo.

PSR - Sim, mas claro dependendo do grau de deficiência de cada aluno.

Pode-se observar nas respostas que para PE se refere que nem sempre o AEE contribui porque depende do grau de comprometimento; A PAEE se refere que a sala de AEE contribui sim para o desenvolvimento do aluno; E para a PSR contribui dependendo da deficiência do aluno. 
No AEE o aluno constrói conhecimento para si mesmo o que é fundamental para que consiga alcançar o conhecimento acadêmico. Aqui, ele não depende de uma avaliação externa, calçada na evolução do conhecimento acadêmico, mas de novos parâmetros relativas às suas conquistas diante do desafio da construção do conhecimento (BRASIL, 2007, p. 27).

É importante que a sala de recursos possa ajudar os alunos em suas atividades, para que haja realmente um processo no ensino-aprendizagem do aluno que precisa dessa sala com os recursos necessários, ou seja, são ambientes dotados de equipamentos, mobiliários e materiais didáticos e pedagógicos.

Por fim, foi-se indagado sobre a formação dos profissionais que atuam no AEE e os professores relataram o seguinte:

PE - Graduação superior e todos tem pós-graduação. Mas o importante é que o município de Teresina ofereça um curso de formação continuada para o AEE.

PAEE - Graduação completa, temos o centro de formação ofertada pelo município.

PSR - Superior Completo, buscamos também alguns externos, no qual arcamos com os gastos.

Segundo as participantes, os cursos de graduação e de pós-graduação são imprescindíveis para o aprimoramento do profissional de educação. Conforme Demo (2007, p. 11): "investir na qualidade da aprendizagem do aluno é acima de tudo, investir na qualidade docente".

Podemos compreender com base no autor que a qualificação docente é um ponto fundamental para a efetivação da política de inclusão, sendo que esta possui papel ativo e intervenção direta junto aos alunos com NEE e necessita, portanto, de formação adequada para atender de forma significativa promovendo o desenvolvimento e a inclusão deste alunado.

Portanto, a formação continuada torna isso possível, garantindo ao profissional de educação meios mais eficazes de construir e produzir no ensino a formação mais abrangente.

\section{Consideraçóes finais}

Por defender a inclusão de alunos com deficiência em classes regulares de ensino e assegurar um desenvolvimento significativo, reconhecendo e valorizando as especificidades, entende-se que é fundamental a remodelação dos sistemas de ensino, bem como uma visão mais positiva da escola, da família e da sociedade em geral no que tange a educaçáo inclusiva. Assim, a partir do objetivo geral que foi analisar a contribuiçáo da sala de AEE para o desenvolvimento dos alunos com necessidades educacionais especiais no ensino fundamental em uma escola em Teresina-PI.

Com vistas a estas realizações afirmamos com base nas respostas do questionário aplicado aos professores que ainda falta muito para a inclusão realmente acontecer, mas que a escola se esforça na medida do possível para atender a todo tipo de necessidades, adquirindo recursos de acordo com a especificidade de cada um, para que se possa ter um atendimento completo e suficiente para desenvolver suas habilidades. Assim, um ponto crucial é a relação entre o professor da sala regular e o da sala de AEE, que planejem juntos açóes pedagógicas voltadas para atingir objetivos e que possam ajudar o aluno no âmbito educacional e social.

Todavia, a escola precisa estar aberta a oferecer condiçóes para receber e atender esse 
público tão especial e capaz de aprender como também de ensinar, oferecendo apoio educacional especializado adequado para todos os alunos. Assim, pressupóe-se que todas as crianças tenham as mesmas oportunidades de acesso, permanência e aproveitamento na escola, independentemente de qualquer particularidade especial que apresentem ou não.

Nesse contexto, o processo de inclusão de crianças com necessidades educacionais especiais no ensino regular ainda é um processo novo em nosso contexto, podendo gerar tensão e ansiedade nas famílias. A facilidade ou a dificuldade com que essas famílias enfrentam esse processo tem relaçáo direta com sua trajetória de vida, dentre outros motivos. Cabe aos profissionais envolvidos estarem alertas para a necessidade constante de atualização de dados sobre as famílias durante todo o processo de inclusão para que possam auxiliá-las, planejando e realizando intervençóes criativas e adequadas às suas necessidades.

Contudo, para que este movimento inclusivo aconteça é fundamental que as crianças com deficiência tenham o apoio de que precisam, seja da família, da sociedade ou nas escolas. Mas, o mais importante de tudo, é que o professor, a família e toda a comunidade escolar estejam convencidos de que cada aluno é diferente no que se refere ao estilo e ao ritmo da aprendizagem.

Esse trabalho é de grande importância para reafirmar para a sociedade que todos merecem uma educação de qualidade, que a inclusão é um direito do aluno com deficiência, para que possa romper com os paradigmas de educação tradicional. E também para conscientizar os futuros professores de quanto é importante a formação continuada e se especializar para estar apto para atender esses alunos que requer uma atenção maior devido as barreiras importas pela sociedade. Que juntos podemos sim rever nossos conceitos do que é educação inclusiva e o que podemos fazer para ajudar nessa inclusão.

\section{Referências}

BRASIL. Ministério da Educação. Secretaria de Educação Especial. Resolução CNE/CEB No 2, de 11 de setembro de 2001. Diretrizes Nacionais para Educação Especial. SEESP/MEC. Brasília: MEC/ SEESP, 2001.

BRASIL. Estatuto da criança e do adolescente: Lei federal no 8069, de 13 de julho de 1990. Rio de Janeiro: Imprensa Oficial, 2002.

BRASIL. Resoluçáo CNE/CP 1, de 18 de fevereiro de 2002. Institui Diretrizes Curriculares Nacionais para a Formação de Professores da Educação Básica. Brasília, 2002.

BRASIL. Constituição (1988). Constituição da República Federativa do Brasil. Brasília, DF: Senado, 1988.

BRASIL. Presidência da República. Lei n. 9.394 de dezembro de 1996. Estabelece as diretrizes e bases da educação nacional. Diário Oficial, Brasília, DF, 23 dez 1996.

BRASIL. Ministério da Educação e Cultura. Secretaria de Educação Especial. Programa educaçáo inclusiva: direito à diversidade, documento Orientador. Brasília: DF, 2005.

BRASIL. Ministério da Educação. Plano de Desenvolvimento da Educaçáo: razóes, princípios e programas. Brasília: MEC, 2007. 
BRASIL. Ministério da Saúde. Secretaria de Atenção à Saúde. Política Nacional de Saúde da Pessoa Portadora de Deficiência. Brasília: Editora do Ministério da Saúde, 2008.

BRASIL. Ministério da Educação. Secretaria de Educação Especial. Política Nacional de Educaçáo Especial na Perspectiva da Educaçáo Inclusiva. 2008.

BRASIL. Presidência da República. Decreto $\mathrm{N}^{\circ}$ 6.949, de 25 de agosto de 2009. Promulga a Convenção Internacional sobre os Direitos das Pessoas com Deficiência e seu Protocolo facultativo, assinado em Nova York, em 30 de março de 2007. Organização das Naçóes Unidas - ONU. Disponívelem: http://www.planalto.gov.br/ccivil_03/_Ato2007-2010/2009/Decreto/ D6949.htm - Acesso em 01/06/2019.

BRASIL. Ministério da Educação. Secretaria de Educação Especial. Política Nacional de Educaçáo Especial na Perspectiva da Educação Inclusiva. Brasília, DF: MEC/SEESP, 2008. Acesso em: 30/05/19.

BRASIL. Ministério da Educação. Secretaria de Educação Especial. Resolução CNE/CEB No 2, de 11 de setembro de 2001. Diretrizes Nacionais para Educação Especial. SEESP/MEC. Brasília: MEC/ SEESP, 2001.

BRASIL. MEC/SEESP. Política nacional de educação especial na perspectiva da educaçáo inclusiva. Brasília, 2008.

DEMO, P. É preciso estudar. In: A.M. de Britto. Memórias de formação: registros e percursos em diferentes contextos. Campo Grande: Ed. da UFMS. 2007.

GIL, A.C. Métodos e técnicas de pesquisa social. 6. ed. - São Paulo: Atlas, 2008.

GARCIA, R.M.C. O conceito de flexibilidade curricular nas políticas públicas de inclusão escolar. In: Jesus, M. D; BAPTISTA,C.B.; VICTOR,S.L.(Orgs.) Inclusão práticas pedagógicas e trajetórias de pesquisa. Porto Alegre: Mediação,2007,340p.

LIBÂNEO, José Carlos; OLIVEIRA, João Ferreira de; TOSCHI, Mirza Seabra. Educação Escolar: políticas, estrutura e organização. São Paulo: Cortez, 2003.

LIBÂNEO, José Carlos. Democratização da escola pública - a pedagogia crítico-social dos conteúdos, 21 a edição, 2006.

MAZZOTTA, Marcos J. S. Trabalho docente e formaçáo de professores de educação especial. São Paulo: EPU, 1993.

NÓVOA, A. (Org.). Profissão professor. Portugal: Porto Editora, 1995.

PRADO, M.E.B.B; FREIRE, F.M.P. A formação em serviços vivendo a reconstrução da prática educacional. In; FREIRE, F.M.P.; VALENTE, A. (Orgs) aprendendo para a vida: os Computadores na sala de aula. São Paulo: Cortez,2001.

RODRIGUES, David. Questôes preliminares sobre o desenvolvimento de políticas de Educação inclusiva. Inclusão: Revista de Educaçáo Especial, Brasília, v.4, n.1, p.33-40, jun. 2008.

ROTTA, Newra Tellecheaet. Transtorno da Aprendizagem: abordagem neurobiológico e multidisciplinar. Porto Alegre: Artmed, 2006. 
SAVINIANI, N. Currículo: um grande desafio para o professor. Revista da Educação. No16. São Paulo, 2003-pg. 35-38.

SILVA, Graziela Patrícia de Oliveira. O projeto político pedagógico e os desafios da inclusáo dos alunos com necessidades educacionais especiais (anees). Brasília, 2014.

VEIGA, Ilma Passos Alecastro. Projeto Político Pedagógico: Uma construção Possível. 19 ed. Campinas, SP: Papirus, 2005.

VYGOTSKY, L. S. A formaçáo social da mente. Martins Fontes. São Paulo,1989. 